\title{
ERRATUM
}

\section{Trapped waves in supersonic and hypersonic turbulent channel flow over porous walls - ERRATUM}

\section{Yongkai Chen and Carlo Scalo}

doi:10.1017/jfm.2021.428, Published by Cambridge University Press, 11 June 2021

The publisher apologises that during the editing process, an error was introduced that resulted in the incorrect placement of ' 5 ' in the corresponding author's affiliation.

The correct affiliation is:

School of Aeronautics and Astronautics, Purdue University, West Lafayette, IN 47906, USA

The online version of this article has been updated

\section{REFERENCE}

Chen, Y. \& SCALO, C. 2021 Trapped waves in supersonic and hypersonic turbulent channel flow over porous walls. J. Fluid Mech. 920, A24. 